\title{
O LÚDICO NA PREVENÇÃO DE ACIDENTES EM CRIANÇAS DE 4 A 6 ANOS
}

\author{
Playing strategies for the prevention of accidents in 4 to 6 \\ years old children
}

Artigo original

\section{RESUMO}

Abordar a prevenção de agravos à saúde no contexto da escola integra as diretrizes das políticas públicas ao se instituir a educação em saúde como tema transversal no ensino fundamental brasileiro. O estudo teve o propósito de descrever a utilização do lúdico como estratégia preventiva de acidentes em crianças no contexto escolar. Trata-se de um relato de experiência com 26 crianças do Jardim I, da Escola de Aplicação Yolanda Queiroz, em Fortaleza. Os dados foram coletados a partir de técnicas de observação e participação de atividades lúdicas como jogos, desenhos, histórias infantis. Os resultados mostraram que os desenhos e as verbalizações das crianças sobre acidentes e sua prevenção corresponderam às expectativas de aprendizado. Considera-se que o uso de atividades lúdicas é uma opção para despertar a criatividade das crianças, mediada pela linguagem do grupo cultural, possibilitando a construção de conceitos essenciais para entender as formas de prevenir acidentes na infância.

Descritores: Criança; Prevenção de Acidentes; Promoção da Saúde.

\section{ABSTRACT}

To broach the prevention of health damages in the school context integrates the public policies rules when health education is established as a transversal subject-matter in the Brazilian elementary education. The study had the purpose of describing the use of playing activities as a preventive strategy against children accidents in the school context. It was an experience report with 26 first grade infant education students from Yolanda Queiroz Application School, in Fortaleza, Brazil. The data were collected by means of observation and participation in playing activities such as games, drawings, infant stories. The results showed that the children's drawings and talks about the accidents and their prevention met the learning expectations. It is considered that the use of playing activities is an option to arise the children creativeness halved by the cultural group language, thus allowing the construction of essential concepts for understanding the ways of preventing childhood accidents.

Descriptors: Child; Accident Prevention; Health promotion.

\section{INTRODUÇÃO}

Abordar a prevenção de agravos à saúde no contexto da escola integra as diretrizes das políticas públicas ao se instituir a educação em saúde como tema transversal no ensino fundamental brasileiro. Nessa vertente torna-se necessário a inclusão nos currículos dos profissionais de saúde desses temas, pois a educação se constitui um meio importante na transformação e repadronização de condutas que proporcionem ambientes saudáveis, diminuindo os fatores de risco que nele existem.
Luiza Jane Eyre de Souza

Vieira $^{(1)}$

Kaline Lucena de Araújo( ${ }^{(2)}$

Ana Maria Fontenelle Catrib ${ }^{(3)}$

Ana Cléa Veras Camurça

Vieira $^{(4)}$

$\left.{ }^{1}\right)$ Enfermeira. Doutora em Enfermagem. Professora Titular do Curso de Graduação em Enfermagem e do Mestrado em Educação em Saúde. Enfermeira da UTI Pediátrica do Instituto Dr. José Frota, Fortaleza, Ceará.

${ }^{2)}$ Aluna do Curso de Enfermagem. ExBolsista do Programa de Iniciação Científica da Fundação Edson Queiroz - PROBIC/

FEQ.

${ }^{3)}$ Pedagoga. Doutora em Educação. Professora Titular do Curso de Graduação em Pedagogia e do Mestrado em Educação em Saúde da Universidade de Fortaleza -

UNIFOR.

4) Terapeuta Ocupacional. Especialista em Psicomotricidade. Professora Assistente do Curso de Terapia Ocupacional da Universidade de Fortaleza - UNIFOR.

Recebido em: 18/05/2004 Revisado em: 15/12/2004 Aceito em: 18/03/2005 
Essa parceria da educação e saúde deverá contribuir para a redução do índice dos acidentes, como também, despertar a necessidade da adoção de atitudes preventivas na família, escola e comunidade.

A família e a escola desempenham papéis importantes para a formação da criança durante as várias etapas de descoberta da vida, cabendo-lhes acompanhar, proteger, educar e favorecer o início da socialização da criança. Consolidar essa parceria é necessário, pois a inter-relação da escola-família requer contínua articulação para que se consiga fortalecer e alcançar propósitos com vistas à construção da cidadania.

A literatura enfoca que a educação é considerada um dos mais importantes recursos na prevenção de acidentes, devendo estar presente em todos os programas com esta finalidade, incluída de forma permanente nas escolas ou outras instituições, para que o processo educativo possa se efetivar ${ }^{(1)}$. A escola constitui-se em espaço ideal para fortalecer a implantação, de "sementes" preventivas em relação aos acidentes com crianças e adolescentes. Embora, a maioria dos acidentes com crianças seja no ambiente doméstico, a escola tem papel fundamental na conscientização da criança quanto aos riscos que permeiam o domicílio e os mecanismos de evitá-los.

A literatura retrata que o ambiente doméstico compreende a estrutura física, o comportamento da família e as atividades desenvolvidas no cotidiano que podem, em determinadas situações, se constituir fator de risco nas ocorrências de acidentes domésticos. No contexto familiar as crianças estão mais vulneráveis a esses acidentes e as famílias supõem que conhecem, muito bem, o ambiente doméstico tornando-se menos vigilantes e, sendo assim, facilitam os acidentes domésticos que têm repercussões indesejáveis. É necessário à família, culturalmente considerada como responsável em promover a segurança e proteção dos seus membros, se conscientize e possa realizar efetivamente esse cuidado preventivo ${ }^{(2-6)}$.

Por outro lado, a escola com filosofia educativa e cidadã, se integra a outros setores na busca da transformação social, podendo ser forte aliada na promoção da saúde. Alianças podem ser estabelecidas para o complexo empreendimento de fazer com que as crianças e adolescentes se transformem em sujeitos de sua saúde, deixando de ser sujeitos das doenças ${ }^{(7)}$.

Nesse sentido, a filosofia da escola promotora de saúde enfatiza que essas ações são construídas no dia-a-dia, conforme o ambiente e a estrutura de que se dispõe. No ambiente escolar é importante que o sentido da vida seja apreendido por todos e que a auto-estima e as habilidades para o bem-viver estejam voltadas para a adoção de uma vida mais saudável. São muitos os desafios que os setores da saúde e da educação têm para efetivar ações de promoção de saúde ${ }^{(8)}$

Fortalecendo a interação da escola e criança, a brincadeira é o momento vivido e lembrado da nossa infância; associar ações preventivas, simulações de casos adotando o lúdico como referencial é uma possibilidade a ser percorrida na tentativa de minimizar as ocorrências de queimaduras, quedas, envenenamentos, aspirações de corpos estranhos, agressões físicas, entre outros que ameaçam a integridade física e social do pequeno cidadão.

Os jogos e as brincadeiras mudaram muito nos diferentes países e contextos sociais, porém o prazer de brincar não mudou e, ao mesmo tempo, o jogo é prazeroso e sério ${ }^{(9)}$. A atividade lúdica, como as demais tradições, é dinâmica e recebe influências da evolução social. A tradição do ato de brincar tem sido vivenciada e modificada a cada geração e a criança, durante o século XX, deparou-se com a ênfase na manipulação de objetos, brinquedos, jogos eletrônicos ${ }^{(10)}$. As crianças necessitam de opções interessantes e motivadoras para participar do mundo. Nesse aspecto, o lúdico tem como potencialidade facilitar a fixação das percepções visual e auditiva porque os estímulos nessas áreas, com contrastes e voltadas para o interesse das crianças, levam à assimilação ${ }^{(10)}$.

A importância do lúdico remete-nos a educação gregoromana, com base nas idéias de Platão e Aristóteles, em que se utilizava o brinquedo na educação, associando a idéia de estudo ao prazer. Na Antigüidade, utilizavam-se dados, assim como doces e guloseimas em forma de letras e números, para o ensino das crianças. A importância da educação sensorial nesse período determinou, portanto, o uso do "jogo didático" por professores das mais diferentes áreas, como filosofia, matemática, estudo das línguas e outras disciplinas ${ }^{(11)}$.

A atividade lúdica encontra um papel educativo no desenvolvimento infantil importante na escolaridade das crianças que vão se desenvolvendo, conhecendo e construindo o mundo, a partir dos intercâmbios sociais, das diferentes histórias de vida das crianças, dos pais e dos professores, que se torna fortalecido pela interação familiar, incorporada à escola. Fica mais fácil de se trabalhar com alunos em um programa de promoção de saúde da criança e do adolescente, quando a tríade escola-aluno-família está coadunada em seus propósitos e expectativas ${ }^{(12)}$.

Este estudo traz à tona algumas premissas básicas: aponta a importância do lúdico na formação do aprendizado da criança, baseando-se que a verdadeira recreação simbólica, dá-se nas idades de 04 a 06 anos, quando a substituição de 
um objeto por outro, na recreação, pode ser observado com frequiência. Este é o ponto de desenvolvimento em que as crianças podem expressar a imaginação, não apenas por meio da linguagem, mas também pelos desenhos, vocalizações e movimentos $^{(13)}$. Outra premissa é sobre a necessidade de estimular a formação de conceitos "cotidianos" ou "espontâneos" que iniciam a partir da atividade prática da criança e de suas interações sociais imediatas ${ }^{(14)}$.

Partindo desses pressupostos, o estudo teve por objetivo descrever a utilização de atividades lúdicas como estratégias preventivas de acidentes em crianças no contexto escolar.

\section{MÉTODO}

Trata-se de um relato de experiência sobre a utilização do lúdico na prevenção de acidentes em crianças de 4 a 6 anos, no contexto de uma escola e representou a primeira etapa de desenvolvimento do Projeto de Iniciação Científica Brincando e Prevenindo Acidentes na Escola que foi financiado pela Fundação Edson Queiroz (FEQ).

Este estudo foi realizado no período de agosto de 2001 a junho de 2003 e envolveu a participação de crianças, famílias e professores discorrendo sobre a temática prevenção de acidentes, onde procurou-se relatar a experiência da utilização de atividades lúdicas como prática educativa, preventiva, vislumbrando uma efetiva consolidação entre a educação e a saúde da criança.

Existindo a necessidade de se inserir na realidade e cotidiano dos sujeitos, a pesquisa qualitativa emergiu como opção metodológica. Esta abordagem possibilita a investigação, amplia e explicita a interação entre o pesquisador e pessoas implicadas na situação investigada facilitando a descrição, registro e análise dessa realidade ${ }^{(15,16)}$.

Assim sendo, participaram do estudo vinte e seis crianças na faixa etária de 04 a 06 anos, alunas do Jardim I do turno da tarde. A seleção dessas crianças se deu de forma intencional, pois a literatura ${ }^{(2-6 ; 16-18)}$ cita que esta fase é a que registra maior incidência de acidentes como quedas, queimaduras, envenenamentos, lesões perfuro-cortantes, entre outros. Como critérios de inclusão estabeleceu-se que a criança estivesse matriculada regularmente na pré-escola e os pais se comprometessem em participar de pelo menos uma reunião educativa durante o período de desenvolvimento do projeto.

A pesquisa desenvolveu-se nas dependências da Escola Yolanda Queiroz, localizada na comunidade do Dendê, no bairro Edson Queiroz, no período de fevereiro a junho de 2002. Esta escola é vinculada às atividades de extensão da Universidade de Fortaleza - UNIFOR, contribuindo para ampliar a atuação acadêmica junto a essa comunidade, incentivando o exercício da cidadania e gestão do autocuidado entre os moradores.

$\mathrm{Na}$ concretização do estudo, inicialmente foi mantido contato com a diretora da escola expondo os objetivos da pesquisa e o compromisso, junto a instituição, sobre a devolução dos resultados. A receptividade da diretora foi amplamente favorável colocando-se à disposição para o desenvolvimento do estudo. Da mesma forma, a professora salientou a importância do projeto referindo ser "interessante a abrangência do projeto", ou seja, o trabalho conjunto da escola e aluno, abordando o tema saúde, incluindo a participação da família para discutirem sobre a importância da prevenção de acidentes em crianças, pois os próprios alunos seriam agentes multiplicadores desse tema em suas residências e comunidade, alertando sobre o perigo dos agravos externos à saúde humana.

O primeiro contato com as crianças aconteceu na sala de aula para apresentação pessoal e explanação sobre o que iria ser desenvolvido coletivamente. As crianças se mostraram receptivas com a idéia de brincar e, ao mesmo tempo, aprender como fazer para evitar os acidentes. Dessa forma, as atividades lúdicas foram planejadas para que todas as crianças participassem na realização de oficinas, jogos, desenhos, histórias infantis e dinâmicas que serviram de estratégias para transmitir informações sobre a prevenção de acidentes na escola. Estas atividades foram realizadas quinzenalmente e semanalmente eram planejadas outras atividades com a professora orientadora do projeto. Utilizouse uma linguagem de fácil entendimento para a faixa etária das crianças e a realização dessas atividades foi registrada pela fotografia, acompanhada pela bolsista e, em alguns momentos, contou com a participação da professora o que contribuiu para facilitar a interação com os alunos.

As técnicas de observação e participação foram realizadas durante o desenvolvimento das atividades lúdicas e, por conseguinte, favorecendo maior aproximação do contexto da pesquisa. Os achados foram registrados no diário de campo com palavras e frases-chave sendo ampliados, posteriormente, para constituir a descrição e reflexão do estudo. A análise dos resultados teve como foco de atenção os seguintes aspectos: verbalização e demonstração de desempenho das crianças; atitudes e procedimentos intergrupal que demonstrassem a preocupação em prevenir acidentes e reprodução de atividades lúdicas relacionadas a prevenção de acidentes. Os aspectos éticos da pesquisa envolvendo seres humanos foram considerados, bem como preservado o anonimato, a isenção de risco dos participantes e seus familiares. 


\section{RESULTADOS}

\section{DESCRIÇÃO DAS PRÁTICAS EDUCATIVAS}

$\mathbf{1}^{\text {a }}$ Atividade - Que tal? Brincar e aprender!

- Objetivo: socialização entre o grupo e a pesquisadora.

- Atividade proposta: montagem de um painel ilustrativo com animais conhecidos pelas crianças, e nesse momento a criança se apresentava dizendo o nome do animal e o próprio nome.

- Resultado: nessa atividade os animais escolhidos pelas crianças em primeiro lugar o cachorro, em segundo o gato e o cavalo por último. A preferência das crianças por esses animais deve-se ao fato da presença desses animais no seu cotidiano.

$2^{\mathbf{a}}$ Atividade - Desenhando os meios de prevenção dos acidentes

- Objetivo: identificar o conhecimento sobre os objetos causadores de acidentes e as medidas de prevenção a partir da percepção das crianças.

- Atividade proposta: desenho livre com lápis de cera, desenvolvido pelas crianças sobre o significado da palavra "acidente", os objetos e os meios de prevenção.

- Resultados: surgiu desenho circular colorido na cor preta e a criança referiu ser "o buraco da queda"; desenharam objetos que foram verbalizados por eles como perigosos para causar acidentes - bicicleta, faca, prego, piscina, pedras, carro, parafuso e deram explicações sobre o significado de cada um, relacionando o tipo de acidente oriundo desses objetos. Desenharam ainda ilustrações que simbolizavam o modo de evitá-los tais como: desenhos de casas com material de limpeza guardados nos armários, janelas fechadas para as crianças não subirem, medicamentos guardados nas últimas prateleiras, tomadas protegidas para as crianças não levarem choque.

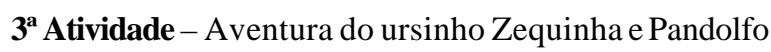
Panda

- Objetivo: facilitar a compreensão das crianças, por meio do conto infantil, sobre a necessidade de adotar atitudes saudáveis.

- Atividade proposta: foi contada uma história enfocando a atenção a saúde e a prática do esporte em que os personagens o ursinho Zequinha e Panda ensinam os outros animais da floresta a praticarem esportes porque é importante para manter a saúde. A fim de facilitar a compreensão das crianças a bolsista adaptou o enredo da história, direcionando-o à prevenção de acidentes, na floresta, entre os animais, além de incluir situações-problema envolvendo a prática de esportes e diversas brincadeiras conhecidas e praticadas pelas crianças no recreio. Foram construídas coletivamente, crianças e bolsista, os meios de prevenção de quedas e outros acidentes que acontecem no contexto domiciliar e escolar.

- Resultados: depois de ouvirem o conto infantil as crianças passaram a vigiar o colega para evitar as quedas e empurrões durante o recreio, chamando atenção uns dos outros, como também da professora sobre a necessidade de se evitar os acidentes.

$4^{a}$ Atividade - Prestando atenção no trânsito

- Objetivo: despertar o interesse e o entendimento sobre as leis do trânsito

- Atividade proposta: aconteceu com a apresentação e explicação sobre o significado do semáforo, e os principais sinais de trânsito, por meio de jogos educativos e montagem com quebra-cabeça versando sobre sinalização no trânsito. Essa atividade foi desenvolvida no pátio da escola em uma pista improvisada que incluía semáforo. Cada aluno recebeu uma identificação de acordo com o seu sinal representado por bolinhas verde, amarelo, vermelho. Simulamos uma "pista" com curvas e paradas que exigiam o uso dos sinais; o sinal vermelho significando parada obrigatória. No amarelo eles deviam prestar atenção e o verde, significava passagem livre para pedestres. Esta atividade coincidiu com uma visita a uma escola de trânsito (atividade que já faz parte das ações educativas da escola) o que contribuiu para despertar a percepção sobre esses sinais e os seus significados. Durante a visita as crianças assistiram uma apresentação e demonstração interativa sobre a sinalização de trânsito com ênfase sobre o significado das luzes do semáforo, relacionando e distinguindo com a ação dos pedestres e dos automóveis. Com o uso de instrumentos apropriados para educar as crianças sobre a legislação do trânsito, essas, novamente tiveram a oportunidade de utilizar os próprios jogos da escola de trânsito (quebra-cabeça) focalizando semáforo e os significados dos sinais de trânsito.

- Resultados: por meio dos jogos educativos sobre a sinalização no trânsito as crianças oportunizaram por meio de experiências individuais e em grupo a importância de obedecer e cumprir as leis de trânsito, bem como o papel do pedestre na prevenção dos acidentes de circulação, os quais requerem muito cuidado e atenção. Por meio das perguntas e dos 
relatos as crianças demonstraram uma aprendizagem satisfatória.

$5^{\mathbf{a}}$ Atividade - Brinco, aprendo e não me acidento!

- Objetivo: construir coletivamente recursos que desenvolvam as habilidades cognitivas por meio das habilidades motoras do recorte e da colagem na produção de painéis ilustrados com mensagens educativas.

- Atividade proposta: as crianças foram divididas em 03 grupos, primeiramente utilizou-se os jogos temáticos em forma de quebra-cabeça e memória, e após foi solicitado que procurassem nas revistas figuras sobre temas relacionados a queimaduras, mordeduras de animais, quedas e colisões, choque elétrico, lesões com instrumento pérfuro-cortante, acidentes de trânsito. Após encontrá-los recortassem e colassem o que resultou em um painel ilustrado com associação dos meios de evitar esses acidentes.

- Resultados: segundo relatos da professora as crianças passaram a agir ativamente sendo vigilantes em situações cotidianas ocorridas em sala de aula, se apropriando da informação procuravam proteger a si mesmo e ao colega na sala de aula, isto é, adotando uma postura de vigilância mútua.

\section{DISCUSSÃO}

Com o intuito de possibilitar maior interação entre as crianças e a bolsista, foi desenvolvida a primeira atividade com o grupo, onde se utilizou um painel ilustrativo com animais e cada criança escolhia o que iria se identificar. Iniciando a atividade referindo o seu nome e do animal escolhido, o animal que mais se sobressaiu foi o cachorro, depois o gato e por último o cavalo.

O brinquedo é importante fonte de promoção ao desenvolvimento da criança, pois o uso dos instrumentos e signos compartilham algumas propriedades importantes; ambos envolvem uma atividade mediada, proporcionando nesse período da pré-escola por meio do brinquedo, a expansão de habilidades conceituais e a imaginação ${ }^{(19)}$.

Neste sentido, as atividades propostas seguem pautadas em aquisições de conceitos e estimulando o imaginário infantil, quando na $2^{\mathrm{a}}$ atividade, ao serem interpelados a expressarem a percepção de acidente por meio de desenhos, descreveram um "buraco" como queda em criança. E isso aponta que a ação numa situação imaginária ensina a criança a dirigir seu comportamento não pela percepção imediata dos objetos ou pela situação que a afeta de imediato, portanto é impossível para a criança muito pequena separar o campo do significado do campo da percepção visual, uma vez que há uma fusão muito íntima entre o significado e o que é visto $^{(19)}$.

A imaginação é um processo psicológico novo para a criança; representa uma forma especificamente humana de atividade consciente, e o brinquedo promove essa situação imaginária, e ensina a criança a dirigir seu comportamento não somente pela percepção imediata dos objetos ou pela situação, mas pelo significado da situação ${ }^{(19)}$.

$\mathrm{Na} 3^{\mathrm{a}}$ atividade ao se apropriar das histórias infantis para levantar questões sobre a prevenção dos acidentes, estimulando as estratégias de manutenção da saúde e prática de esportes utiliza-se a brincadeira de faz-de-conta (20) provocando uma situação imaginária e ao mesmo tempo regida por regras, estimulando que a criança se comporte de forma mais avançada do que o habitual, agindo diretamente nas mudanças comportamentais da criança. Adaptação do contexto da história ao tema da prevenção de acidentes resultou na aquisição, pelo menos temporária, de um olhar vigilante sobre o modo das crianças brincarem no recreio.

Nesse sentido, as histórias infantis tornam-se promotoras em saúde por invocarem o potencial libertador e criativo da palavra. Por meio da literatura, a criança vê os desenhos, ilustrações ou imagens dos livros de histórias e, ouvindo alguém explicar ou narrar o que ela está vendo, começa a aprender, inconscientemente, que o mundo existe a partir de uma nomeação, e esse será o ponto de partida para se chegar a determinado conhecimento é nomear o objeto ou o fenômeno em foco.

Diante desse contexto, entende-se que aprender por meio da recreação para a criança é extremamente habitual para a criança, na medida que essa ação faz parte de sua competência, possibilitando a entrada em seu mundo com o objetivo de coletar informações importantes que irão contribuir para projetar e desenvolver atividades inerentes aos papéis e direcionadas às áreas subjacentes de necessidades ${ }^{(13: 74)}$.

Nesse universo observamos na $4^{\mathrm{a}}$ atividade que o acesso aos objetos é mediado, por meio de recortes do real operados pelos sistemas simbólicos ${ }^{(20)}$, e nesta perspectiva os sinais de trânsito apresentados as crianças por meio dos jogos educativos, promoveram momentos em que a brincadeira estimulou processos psicológicos superiores como: a percepção, a atenção e a memória, a partir da mediação simbólica e da origem sócio-cultural desses instrumentos, facilitando o aprendizado e a compreensão com participação coletiva.

A literatura nos mostra que a idéia de um ensino despertado pelo interesse do aprendiz acabou transformando 
o sentido do que se entende por material pedagógico em cada aprendiz, independente de sua idade, passou a ser um desafio à competência do educador. Nesse contexto, os jogos ganham espaço como ferramenta ideal da aprendizagem, na medida que estimula o interesse do aprendiz, ajuda-o a construir novas descobertas, desenvolve e enriquece sua personalidade e simboliza um instrumento pedagógico que leva ao ensinador a condição de condutor, estimulador e avaliador da aprendizagem ${ }^{(21)}$.

Utilizando os jogos e relacionando alguns objetos (faca, prego, serrote, tomada, porta, janela, etc) com o tipo de acidente que este poderia ocasionar sugeriu-se a $5^{\mathrm{a}}$ atividade, uma com o tema de prevenir os acidentes arte, brincadeira e uma extrema seriedade. Parafraseando a literatura concordamos com a assertiva de que por meio do ato de brincar, a criança desenvolve estratégias de aprendizagem (...) assim como necessitam de opções interessantes e motivadoras para participarem do mundo ${ }^{(22)}$.

Entendemos que um dos objetivos da escola é facilitar a aquisição do conhecimento de geração para geração e, além da qualidade e metodologias escolhidas para tal fim, não se deve esquecer de que ensinar é, principalmente, ensinar a aprender $^{(19)}$.

As atividades desenvolvidas entre professores, mães e bolsista no ambiente escolar contribuíram como fontes de modelos de aprendizagem, por meio das construções coletivas puderam mediar as construções infantis, por meio do ato de brincar juntos, no assentar-se ao lado, no tocar, no olhar, no sorriso dirigido, no interesse pela ação do companheiro, na troca de experiência, na busca de motivos para interagir e criar no espaço da sala de aula as atividades conjuntas.

Durante as atividades a linguagem como o sistema simbólico $^{(20)}$ fundamental na mediação entre o sujeito e o objeto favoreceu a apropriação dos processos de abstração e generalização compartilhando os significados pelos usuários. Porém percebia-se entre as crianças manifestações fisiológicas de emoção, na qual a consciência afetiva manifestou-se por meio de um querer bem que contribuiu para que elas aparentassem calma e mais concentração nas atividades escolares.

O lúdico, como elemento que estrutura a vida das crianças, se constituiu como coadjuvante nas formas de organização, criação de diferentes tipos de relações de maneira singular, como sociabilidade com o prazer, foi também ruptura, acontecimento, manifestou repetição, negação, movimento, dinamismo, astúcia, duplicidade e vitalismo $^{(9)}$.

\section{CONSIDERAÇÕES FINAIS}

Este estudo fez parte de um projeto de iniciação científica cujo desenvolvimento envolveu a participação da criança, família e professores discutindo sobre estratégias de prevenção de acidentes em crianças, abrangendo o contexto domiciliar e escolar. Ao priorizar a utilização do lúdico como estratégia educativa e preventiva com crianças de 4 a 6 anos, foi observado que houve grande envolvimento das crianças na construção coletiva das atividades lúdicas desenvolvidas. As crianças assumiram ativamente o lugar de sujeitos e com competência e compromisso construíram e interagiram na formação de conceitos sobre a prevenção dos acidentes, transformando a brincadeira em estratégia para a promoção da saúde.

A utilização do lúdico em práticas educativas é descrita como elemento integrador às estratégias de educação em saúde, despertando nas crianças o entendimento de situações reais, mediadas pelo brinquedo, essas ações deverão ser incentivadas na pré-escola, utilizando a linguagem do grupo cultural onde a criança se desenvolve e dirige o processo de formação de conceitos.

\section{REFERÊNCIAS}

1. Pelicioni MCF, Gikas RM. Prevenção de acidentes em escolares: proposta de metodologia de diagnóstico para programa educativo. Rev Bras Saúde Esc. 1992 Jan;2(1):23-6.

2. Souza LJEX. Envenenar é mais perigoso: uma abordagem etnográfica [dissertação]. Fortaleza (CE): Universidade Federal do Ceará. Curso de Mestrado em Enfermagem; 1997.

3. Souza LJEX, Barroso MGT. Fator de risco no contexto familiar. In: Alves MDS, Pagliuca LMF, Barroso MGT, organizadores. Cultura e poder nas práticas de saúde: sociedade, grupo, família. Fortaleza: Pós-Graduação/ DENF/UFC; 1999. p.117-125.

4. Rocha JHS, Vieira LJES. Queimaduras: o quente é prevenir! In: Resumos do II Encontro de Pós-Graduação e Pesquisa da Uiniversidade de Fortaleza; 2002 Abril 22-24; Fortaleza, CE; 2002.

5. Vieira LJES. Julgar e compreender: contradições da abordagem multiprofissional à família da criança envenenada [tese]. Fortaleza (CE): Universidade Federal do Ceará.Programa de Pós-Graduação em Enfermagem; 2002 . 
6. Araújo KL, Vieira LJES. A criança e os fatores de risco no ambiente domiciliar e escolar: um ensaio reflexivo. Texto Contexto Enferm. 2002 Set-Dez; 11(3):83-7.

7. Ferriani MGC, Gomes R. Saúde escolar: contradições e desafios. Goiânia: AB Editora; 1997.

8. Menezes BL, Catrib AMF. Educação em saúde no espaço escolar. In: Resumos do VIII Encontro de Iniciação à Pesquisa da UNIFOR; 2002 Set 16-18; Fortaleza, CE; 2002.

9. Friedmann A. Brincar: crescer e aprender. O resgate do jogo infantil. São Paulo: Moderna; 1996.

10. Munguba MC. Videogame: estratégias de aprendizagem. Visão do terapeuta ocupacional para o século XXI. Aporte para terapeutas ocupacionais, educadores e pais. Fortaleza: Universidade de Fortaleza; 2002.

11. Vial J. Jeu et éducation: les ludothéques. Paris: Presses Universitaires de France; 1981.

12. Wajskop G. Brincar na pré-escola. $3^{\text {a }}$ ed. São Paulo: Cortez; 1999.

13. Fazio LS. Contar histórias, inventar histórias e a recreação fantasiosa. In: Parham LD, Fazio LS. A recreação na terapia ocupacional pediátrica. São Paulo: Santos; 2000. p.233-47.

14. Oliveira MK. Vygotsky e o processo de formação de conceitos. In: La Taille Y, Oliveira MK, Dantas H. Piaget, Vygotsky, Wallon: teorias psicogenéticas em discussão. São Paulo: Summus; 1992. p.23-34.

15. Minayo MCS, Deslandes SF, Cruz Neto O, Gomes R. Pesquisa social: teoria, método e criatividade. $19^{\mathrm{a}}$ ed. Petrópolis: Vozes; 2001.
16. Souza LJEX de, Rodrigues AK de C, Barroso MGT. A família vivenciando o acidente doméstico: relato de experiência. Rev Latino-Am.Enferm. 2000; 8:83-9.

17. Alcântara DA, Vieira LJES, Albuquerque VLM. Intoxicação medicamentosa em criança. Revista Brasileira em Promoção da Saúde. 2003; 16:10-6.

18. Vieira LJES, Silva AND, Frota MA, Albuquerque VLM. Envenenamento por carbamato em crianças: estudo descritivo. Revista Brasileira em Promoção da Saúde. 2004; 17:193-9.

19. Rego TC. A cultura torna-se parte da natureza humana. In: Rego TC. Vygotsky: uma perspectiva históricocultural da educação. 11 $1^{\mathrm{a}}$ ed. Petrópolis: Vozes; 2001. p.37-83.

20. Vygotsky LS. A formação social da mente. São Paulo: Martins Fontes; 1998.

21. Fonseca LMM, Scochi CGS. Inovando a assistência de enfermagem ao binômio mãe-filho em alojamento conjunto neonatal através da criação de um jogo educativo. Rev Latino-Am. Enferm. 2000;8:106-8.

22. Munguba MC, Valdés MTM, Matos VC, Silva CAB. Jogos eletrônicos: apreensão de estratégias de aprendizagem. Revista Brasileira em Promoção da Saúde. 2003;16:39-48.

\section{Endereço para correspondência:}

Luiza Jane Eyre de Sousa Vieira

Universidade de Fortaleza

Mestrado em Educação em Saúde

Av. Washington Soares 1321 Edson Queiroz

E-mail: janeeyre@unifor.br 